Article

\title{
Enhanced Efficiency of Thermoelectric Generator by Optimizing Mechanical and Electrical Structures
}

\author{
Jinlong Chen ${ }^{1}$, Kewen $\mathrm{Li}^{1,2, *}$, Changwei Liu ${ }^{1}$, Mao Li ${ }^{3}$, Youchang $\mathrm{Lv}^{3}$, Lin Jia ${ }^{1}$ \\ and Shanshan Jiang 1 \\ 1 School of Energy Resources, China University of Geosciences (Beijing), Beijing 100083, China; \\ loongchen@cugb.edu.cn (J.C.); changweiliu@outlook.com (C.L.); jialin@cugb.edu.cn (L.J.); \\ shanshanj@cugb.edu.cn (S.J.) \\ 2 Department of Energy Resources Engineering, Stanford University, Stanford, CA 94305, USA \\ 3 State Key Laboratory of Development and Utilization of Coking-coal Resources, \\ China Pingmei Shenma Group, Pingdingshan 467000, China; zm13721869229@126.com (M.L.); \\ gmc109@126.com (Y.L.) \\ * Correspondence: likewen@cugb.edu.cn
}

Received: 23 July 2017; Accepted: 31 August 2017; Published: 4 September 2017

\begin{abstract}
Much attention has been paid to the application of low temperature thermal resources, especially for power generation in recent years. Most of the current commercialized thermal (including geothermal) power-generation technologies convert thermal energy to electric energy indirectly, that is, making mechanical work before producing electricity. Technology using a thermoelectric generator (TEG), however, can directly transform thermal energy into electricity through the Seebeck effect. TEG technology has many advantages such as compactness, quietness, and reliability because there are no moving parts. One of the biggest disadvantages of TEGs is the low efficiency from thermal to electric energy. For this reason, we redesigned and modified our previous $1 \mathrm{KW}$ (at a temperature difference of around $120^{\circ} \mathrm{C}$ ) TEG system. The output power of the system was improved significantly, about $34.6 \%$ greater; the instantaneous efficiency of the TEG system could reach about $6.5 \%$. Laboratory experiments have been conducted to measure the output power at different conditions: different connection modes between TEG modules, different mechanical structures, and different temperature differences between hot and cold sides. The TEG apparatus has been tested and the data have been presented. This kind of TEG power system can be applied in many thermal and geothermal sites with low temperature resources, including oil fields where fossil and geothermal energies are coproduced.
\end{abstract}

Keywords: thermoelectric generator system (TEGs); direct power generation; thermoelectric effect; thermal efficiency

\section{Introduction}

Geothermal energy resources are renewable and exist widely. If carefully managed, geothermal production can be sustained essentially and almost indefinitely [1]. A lot of geothermal resources belong to the low-temperature category, they are being used in combined heat and power plant (CHP). For water with a temperature below $100^{\circ} \mathrm{C}$, binary (Organic Rankine Cycle) power plants are usually installed and used to generate electricity [2,3]. An example is the former USSR binary power plant, $680 \mathrm{KW}$ using $81{ }^{\circ} \mathrm{C}$ water at Paratunka on the Kamchatka peninsula [4]. Other methods of waste heat recovery (WHR) that can be applied at low temperature differences with relatively high efficiency, like Texergy cycle [5], trigeneration cycle [6], thermochemical recuperation [7-9], cooling or heating [10,11].

$\mathrm{Li}$ et al. [12] discussed possible factors which have led to the low growth rate of geothermal development. The main factors include high exploration risk, lower social acceptance, long payback and construction time and difficulty to assess resources. Li et al. [12] also pointed out the development 
and utilization of thermoelectric generator (TEG) technology may be one of the possible solutions and a direction to speed up geothermal growth. Liu et al. [13] built a power generator using TEG modules, which indicated that the cost of the TEG system developed was lower than those of photovoltaic (PV) and wind power systems in terms of equivalent energy generated.

From the beginning of the 1990s a renewal of interest in thermoelectric (TE) appeared, due to environmental concern with refrigerant gas and greenhouse effects, as well as the need to develop alternative energy sources [14].

One of the big disadvantages of TEGs is the low efficiency from thermal to electric energy because of many factors affecting the output power of thermoelectric generators. In the last few decades, immense efforts have been made to study thermoelectric generator applications experimentally. Zheng et al. [15] reviewed the thermoelectric technology, demonstrated its potential to improve energy efficiency and pointed to a possible direction of alleviating energy demand. Due to the advantages of no moving parts, long lifespan and quiet operation, attempts to use thermoelectric modules have been made in many areas, such as the automobile, aerospace, industry and domestic sectors. Demir and Dincer [16] investigated a water-electric cogeneration system integrated with a TEG, the system has 21.8 MW of generating electricity capacity. Niu et al. [17] developed a low-cost, simple configuration TEG unit with commercially available $\mathrm{Bi}_{2} \mathrm{Te}_{3}$ based thermoelectric modules for an anticipated maximum power generation of about 150-200 W level. Chen et al. [18] researched the characteristics of a multi-element thermoelectric generator with the irreversibility of finite-rate heat transfer, Joule heat inside the thermoelectric device, and the heat leak through the thermoelectric couple leg. Crane and Jackson [19] studied optimizing TE waste heat recovery by integrating efficient cross flow heat exchangers with thermoelectric modules for conversion of waste heat to electricity. Hsu et al. [20] made efforts in simulating and testing the performance of $\mathrm{Bi}_{2} \mathrm{Te}_{3}$-based TEG modules, $12.41 \mathrm{~W}$ of maximum power output at an average temperature difference of $30 \mathrm{~K}$ for 24 TEG modules.

Rodríguez et al. [21] developed a TEG model which takes into account the properties of the thermoelectric materials as a function of temperature, studied the behavior of the thermoelectric generator and made improvements to the previously published model. Bélanger and Gosselin [22] presented a model and optimized the internal structure of a thermoelectric generator sandwiched in a cross flow heat exchanger. Ming et al. [23] carried out a numerical simulation to verify the validity of the optimum segmented thermoelectric generator (STEG) model in the design boundary condition. The results indicated that unsteady heat flux not only affects the output of the model, but also deteriorates the work environment. Esarte [24] developed a theoretical expression for the temperature through the TEG module and checked with the experimental results. The theoretical results meet well with the experimental values for low flow rates but not for high flow rates. Gou et al. [25] studied the influence of heat transfer irreversibility on thermoelectric generation performance. Expanding the heat sink surface area and enhancing cold-side heat transfer capacity in a proper range can enhance performance of the TEG system. Casano and Piva [26] reported an experimental investigation of the performance of a power generation device in which they used multiple Peltier modules in the Seebeck mode, and analyzed the thermoelectric generator based on the experimental data for the 'open' and 'closed' circuit voltage, electric power output and conversion efficiency as a function of temperature.

Chen et al. [27] presented a three-dimensional (3D) numerical solution to the fluid-structure coupled problem by implementing a FLUENT compatible thermoelectric model. Yu and Zhao [28] presented a detailed numerical model of thermoelectric generator with the parallel-plate heat exchanger, focused on analyzing the fluid temperature changes along the fluid passage and the temperature difference cross the thermoelectric modules (TE). Meng et al. [29] established a complete numerical model of commercial thermoelectric generator with finned heat exchangers, considered the heat transfer irreversibilities between the device and its external reservoirs, analyzed the effects of external irreversibilities on the performance of the thermoelectric generators compared with the exo-reversible model. Many researches have investigated the numerical modeling of TEG systems. Gou et al. [30] established a theoretical dynamic model of a thermoelectric generator for waste heat recovery and 
discussed the influence of the flow rates of hot and cold fluids, which indicated that enhancing heat dissipation on the cold side takes greater importance compared with enhancing heat transfer.

In this paper, we redesigned and modified our previous $1 \mathrm{KW}$ (at a temperature difference of around $120^{\circ} \mathrm{C}$ ) TEG system. The output power of the system was improved significantly, about $34.6 \%$ greater; the instantaneous efficiency of the TEG system could reach about $6.5 \%$. Laboratory experiments have been conducted to measure the output power at different conditions: different connection modes between TEG modules, different mechanical structures, different fluid flow direction, and different temperature differences between hot and cold sides. The TEG apparatus has been tested and the data will be presented.

\section{Experimental}

A schematic diagram of the experiment is shown in Figure 1. The temperature on the hot side was kept at a given constant value $\left(40,50,60,70,80,90\right.$ or $\left.100^{\circ} \mathrm{C}\right)$ by a thermostat water bath, and the cold side with a constant temperature was kept at about $20^{\circ} \mathrm{C}$, which was controlled by the tap water. The temperature of hot and cold sides was within a margin of error of three percent and five percent respectively. The average temperatures of the hot and cold sides were measured by two micro-thermocouples. The values of voltage, current and power were collected by the multi-meter devices. Incremental conductivity method was used to achieve the maximum power tracking as the load resistance was the optimum value [31,32]. In this study, the temperature of the hot side is represented by $T_{h}$, and the cold side is $T_{c}$, in addition, the temperature difference between hot and cold sides is referred to as $\Delta T\left(\Delta T=T_{h}-T_{c}\right)$.

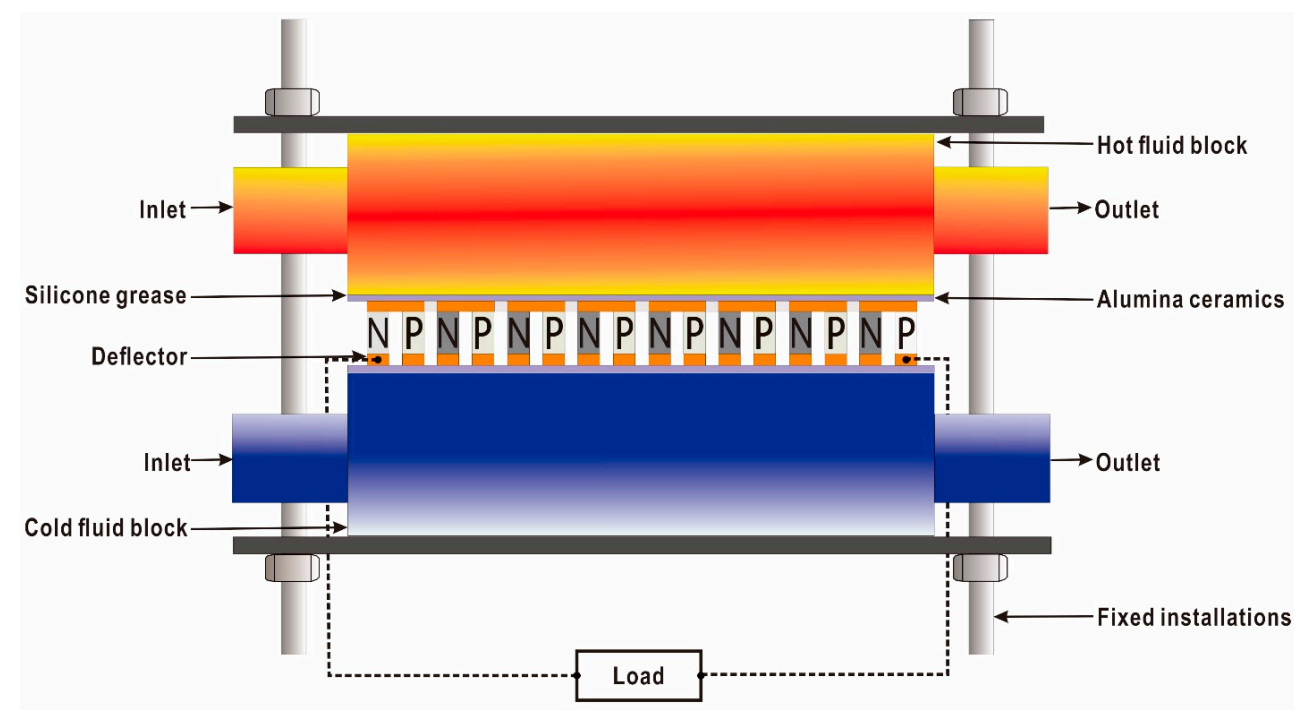

Figure 1. Schematic of the thermoelectric generator.

\section{Characteristics of Internal Resistance}

The internal resistance of the thermoelectric module affects the current that goes through it, finally determining the output power. Therefore, it is crucial to study the internal resistance characteristics.

The $\Delta T$ of single thermoelectric modules was increased from 50 to $90{ }^{\circ} \mathrm{C}$ with an interval of $10{ }^{\circ} \mathrm{C}$, the experimental results are shown in Figure 2. 


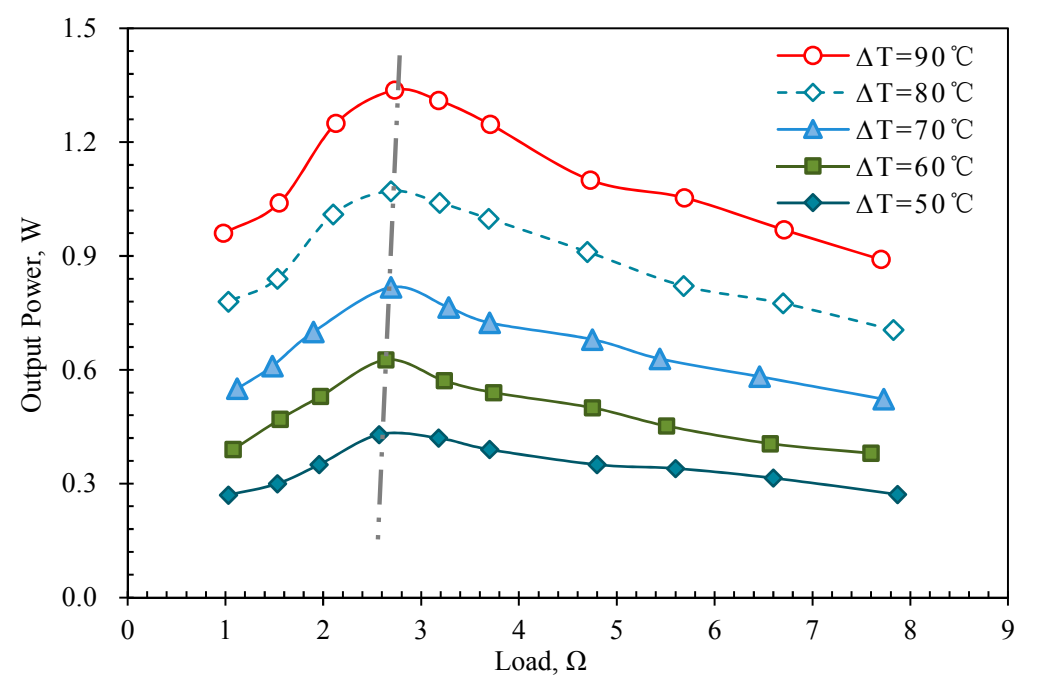

Figure 2. The relationship between load and output power for single module at different $\Delta T$.

As shown in Figure 2, a small-scale increase of output power appears at the initial development period. With the increase in load, the output power increases first then decreases gradually. The output power comes to the maximum when the load is equal to the internal resistance, these results conform to the Closed Circuit Ohm's Law. The dash line describes the optimum resistance that has an increasing tendency at different $\Delta T$, varying from 50 to $90{ }^{\circ} \mathrm{C}$. It seems to be a phenomenon that increasing temperature difference leads to the internal resistance of thermoelectric module increasing due to the characteristics of thermoelectric materials in a specific temperature range [33].

In addition, the resistances of multiple thermoelectric modules were tested at different $\Delta T$, increasing from 20 to $80^{\circ} \mathrm{C}$, and then the studies on a number of thermoelectric modules in series were conducted. The experimental results are presented in Figures 3 and 4.

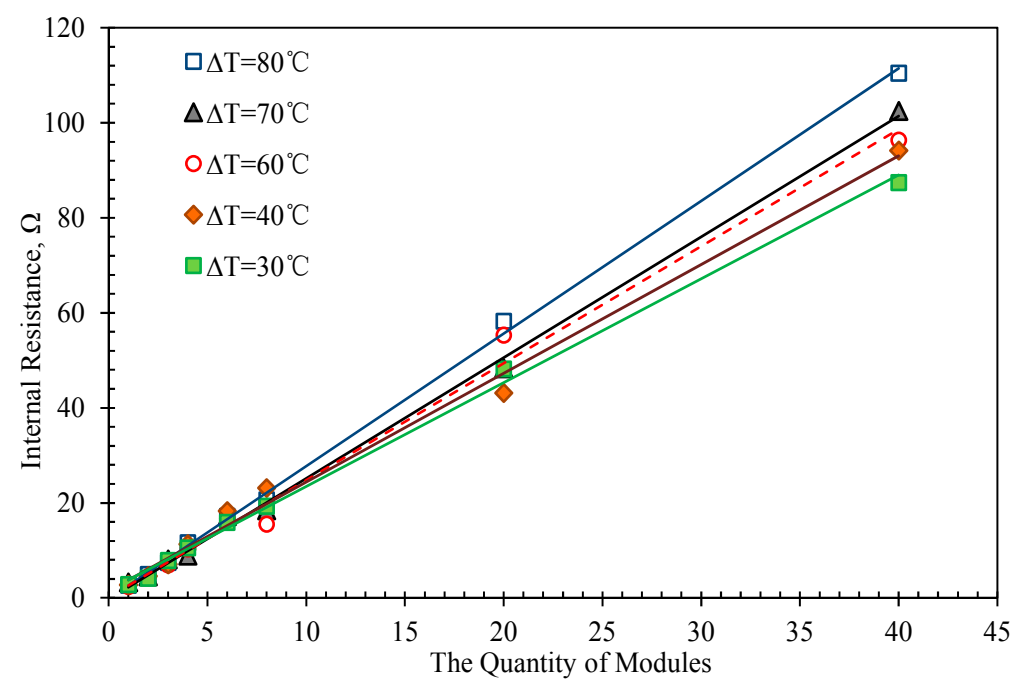

Figure 3. Relationship between total internal resistance and quantity of modules in series. 


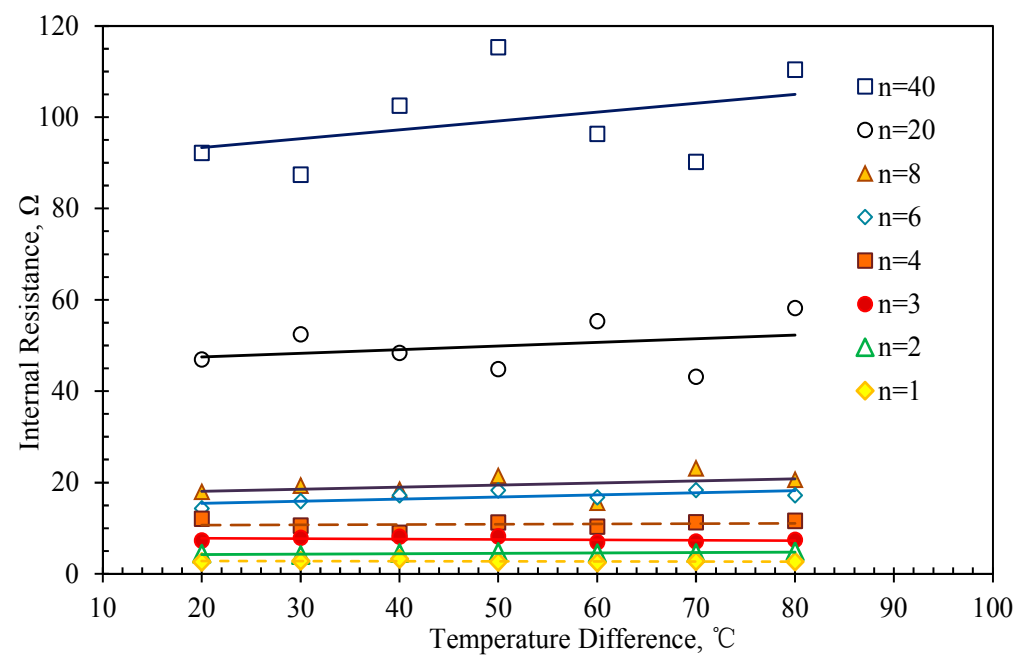

Figure 4. Relationship between internal resistance and $\Delta T$ for different quantity of modules ( $n$ in the diagram is the number of thermoelectric modules in series).

Figure 3 demonstrates a linear relationship between the total internal resistance and the quantity of modules when $\Delta T$ is constant. Figure 4 reveals the fluctuation range of internal resistance for a different number of modules, when $\Delta T$ is increasing from 20 to $80^{\circ} \mathrm{C}$. Obviously, for 4 modules, the maximum fluctuation range of their internal resistance is about $5.6 \%\left(R_{\mathrm{Min}}=8.9 \Omega\right.$ at a $\Delta T$ of $40{ }^{\circ} \mathrm{C}$; $R_{\mathrm{Max}}=11.6 \Omega$ at the $\Delta \mathrm{T}$ of $80{ }^{\circ} \mathrm{C}$ ); for 20 modules, it is around $10.6 \%$, and for 40 modules, $15.3 \%$. The results illustrate that the fluctuation range of total resistance for multiple modules increases as the number of modules increases. The resistivity of the thermoelectric material is changed in a specific temperature range [33], and the increasing quantity of modules may amplify the internal resistance fluctuation. Therefore, stabilizing the internal resistance may be a key issue for thermoelectric power generation development.

\section{Factors Affecting Output Power}

Today, many studies regarding thermoelectricity are focused on material improvement. Less attention has been paid to the device and system optimization. The heat exchanger system is the most important part in optimized measurement and the TEG system, therefore, experimental study was focused on the structure, reinforcement, insulation measures, fluid flow direction, and flow rate of the heat exchanger, by providing a relevant experimental basis for the following study on the TEG module.

\subsection{Effect of Heat Exchanger Structure}

The heat exchanger surface has a direct relationship with the contact thermal resistance between heat exchanger and thermoelectric module. In addition, the fluid channel's shape of the heat exchanger also affects the heat transfer efficiency. Therefore, three kinds of plate heat exchanger models with the same material but different structures were selected as the research object whose properties can be seen from the data in Table 1. The schematic diagram and the structures of three models are shown in Figures 5 and 6 . 


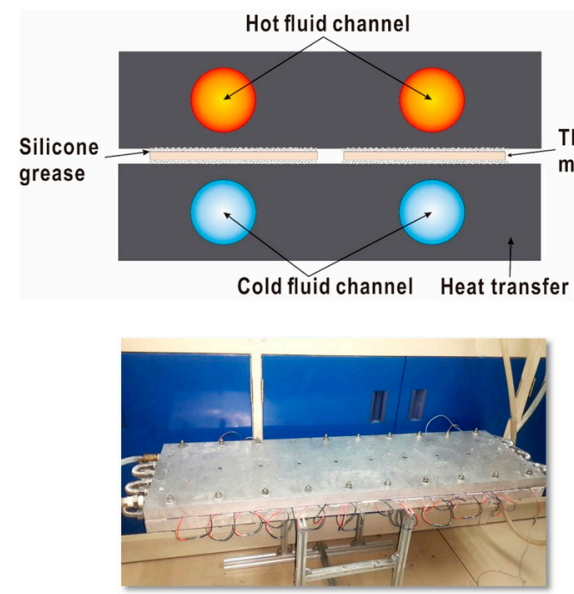

(a)

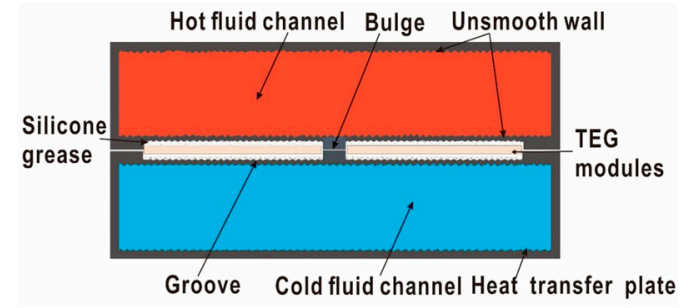

(c)
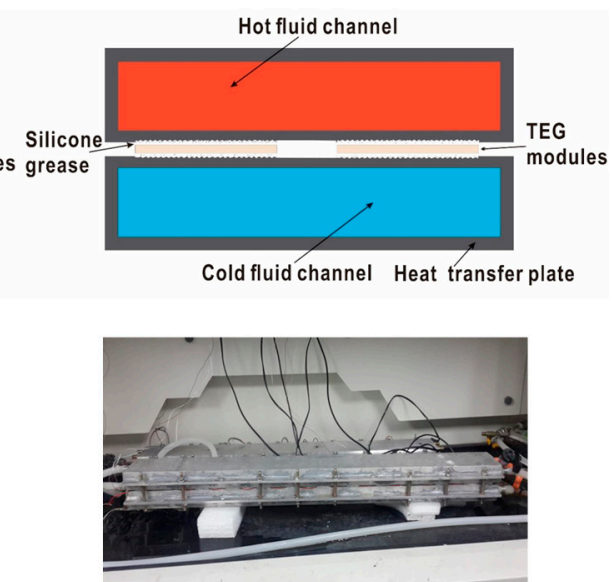

(b)

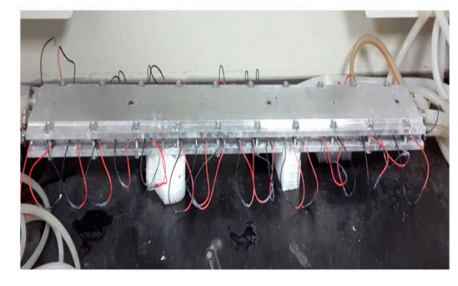

Figure 5. Different model structure: (a) Structure diagram of Model \#1; (b) Structure diagram of Model \#2; (c) Structure diagram of Model \#3.

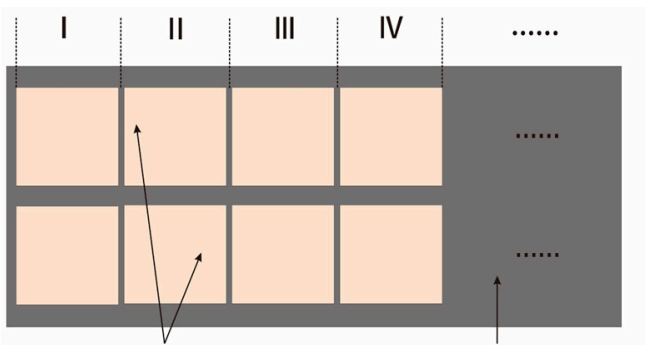

TEG modules

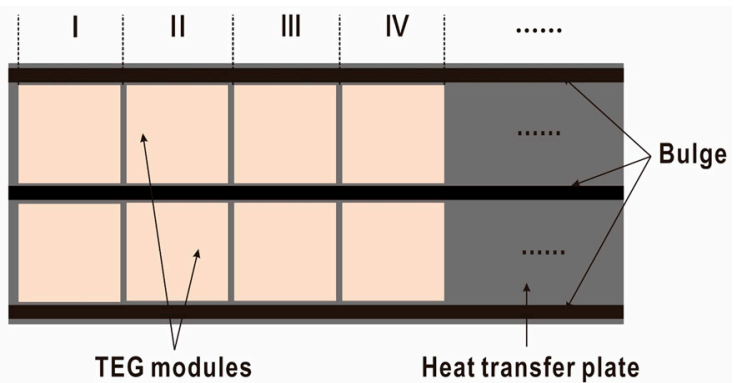

(b)

Figure 6. (a) Contact form between module and heat exchanger of Model \#1 and \#2; (b) Contact form between module and heat exchanger of Model \#3.

Table 1. The structure comparison of Models \#1, \#2 and \#3.

\begin{tabular}{|c|c|c|c|c|c|c|}
\hline Model & $\begin{array}{l}\text { Fluid Channel } \\
\text { Shapes }\end{array}$ & $\begin{array}{c}\text { Quantity } \\
\text { of Module }\end{array}$ & $\begin{array}{l}\text { Dimensions } \\
(\mathrm{mm})\end{array}$ & $\begin{array}{c}\text { Fluid Channel } \\
\text { Cross-Sectional Area }\left(\mathrm{cm}^{2}\right)\end{array}$ & $\begin{array}{l}\text { Wall Thickness } \\
\text { (mm) }\end{array}$ & $\begin{array}{c}\text { Volume } \\
(\mathrm{mL})\end{array}$ \\
\hline $\begin{array}{l}\text { Model } \\
\# 1\end{array}$ & Through-hole & 40 & $1000 \times 100 \times 30$ & 3.14 & 5 & 314 \\
\hline $\begin{array}{l}\text { Model } \\
\quad \# 2\end{array}$ & N-type boxes & 40 & $1000 \times 100 \times 50$ & 36 & 5 & 3600 \\
\hline $\begin{array}{l}\text { Model } \\
\quad \# 3\end{array}$ & $\begin{array}{l}\text { Rough surface } \\
\text { boxes }\end{array}$ & 40 & $1000 \times 100 \times 18$ & 11.28 & 3 & 1128 \\
\hline
\end{tabular}

${ }^{1}$ Volume: the volume of fluid flow channel.

The output power of Models \#1, \#2 and \#3 is tested at different $\Delta T$ from 40 to $80{ }^{\circ} \mathrm{C}$, and the results are shown in Figure 7. 


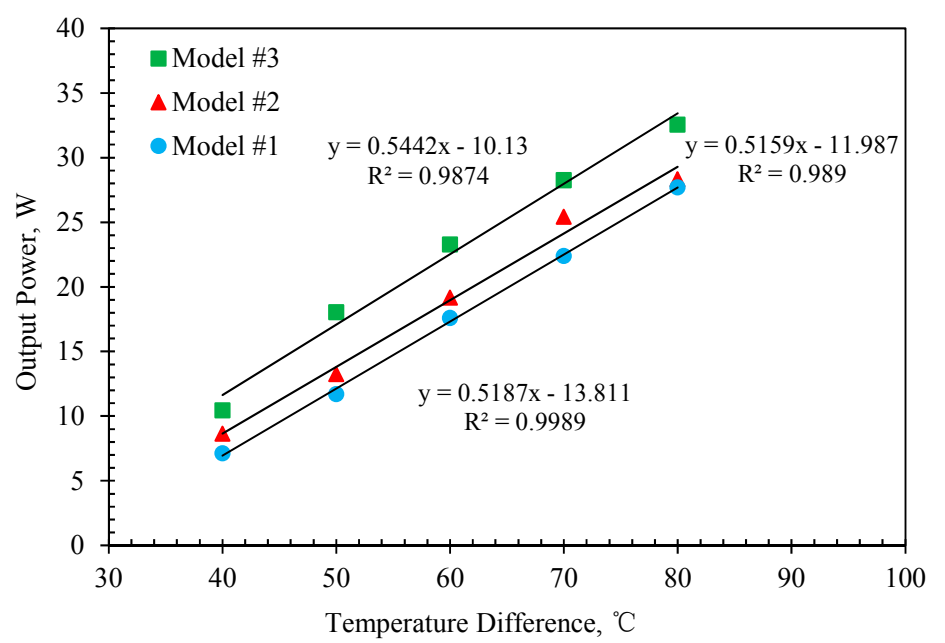

Figure 7. Relationship between $\Delta T$ and maximum output power in different models.

Figure 7 indicates that the maximum output power of Models \#1,\#2 and \#3 is 7.1, 8.6 and $10.45 \mathrm{~W}$ respectively for 40 thermoelectric modules at a $\Delta T$ of $40{ }^{\circ} \mathrm{C}$. When the $\Delta T$ increases to $80^{\circ} \mathrm{C}$, the maximum output power of Models \#1, \#2 and \#3 goes up to 27.7, 30.3, and $32.5 \mathrm{~W}$ respectively. These results suggest that the overall performance of Model \#3 is more stable than that of Models \#1 and \#2. All the improvements of the heat exchanger are embodied in the structure design, and reflected in the level of power change of a heat exchanger model, which was composed of 40 thermoelectric modules only. The advantage of Model \#3 will be enlarged greatly when a series of heat exchangers are assembled for a TEG system.

As shown in Figure 5a, the fluid channels of Model \#1 are connected in series; the fluid flow direction was selected co-current (the heat fluid flow direction is the same as the cold fluid flow direction). The structure of Model \#1 is relatively simple and the thicker wall limits the heat conduction, which reduces the thermoelectric conversion efficiency of the whole model. Thermoelectric modules on the surfaces of Models \#1 and \#2 are relatively loose, which can be seen from Figure 6a.

According to Figure $5 b$, the structure of Model \#2 is comparatively reasonable, the larger volume of fluid channel cross-sectional area and the thinner wall thickness contribute to the heat conduction, which may improve the overall thermoelectric conversion efficiency to a certain extent. Nevertheless, the surface of the fluid channel is smooth, which may not help to increase heat transfer efficiency. Compared with Model \#1, the problems of poor compactness between thermoelectric modules and heat exchanger in Model \#2 are still not improved.

Based on Model \#1 and Model \#2, Model \#3 employs embedded methods, and its structure diagram is shown in Figure 5c. The thermoelectric modules were embedded in the bulge which was installed in the middle of the heat exchanger plate, as shown in Figure $6 \mathrm{~b}$, and the space between the two bulges placed in two rows of the thermoelectric modules. The structure of Model \#3 ensures the compactness between thermoelectric modules and heat exchanger when the pressure is applied to the heat exchanger, the thinner wall can increase heat conduction, the rough treatment inside the fluid channel makes the contact area of the fluid and the fluid channel increase greatly, all these measures contribute to the increasing conversion efficiency of TEG.

\subsection{Effect of Heat Exchanger Reinforcement}

The TEG system requires a high degree of compactness; besides conventional fixed methods which just reinforced pressure at either side of heat exchanger, the reinforcement measures also added pressure at the central part. This may improve the stress distribution uniformity and the compactness between thermoelectric modules and heat exchanger system. The value of $\Delta T$ was controlled and 
ranged from 40 to $80^{\circ} \mathrm{C}$, the results of the maximum output power before and after the application of reinforcement measures at the same $\Delta T$ for Model\#1 is shown in Figure 8.

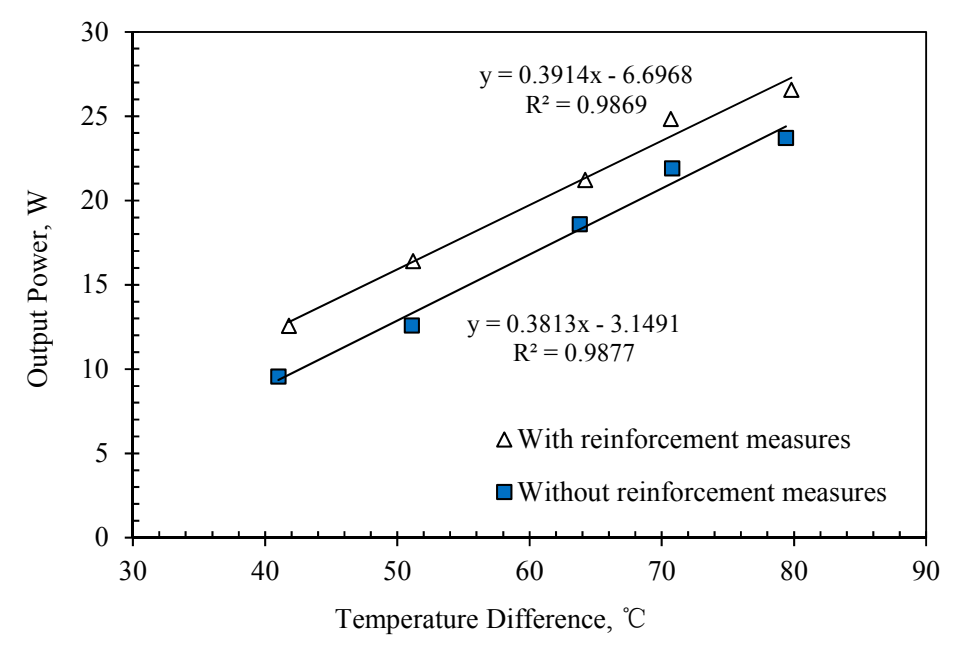

Figure 8. The effect of reinforcement measures on output power.

Figure 8 indicates that the maximum output power is $12.5 \mathrm{~W}$ without reinforcement measures, and $16.4 \mathrm{~W}$ with reinforcement measures when the $\Delta T$ is about $50{ }^{\circ} \mathrm{C}$. The maximum output power is $23.7 \mathrm{~W}$ without reinforcement measures, and $26.5 \mathrm{~W}$ with reinforcement measurements when $\Delta T$ is about $80{ }^{\circ} \mathrm{C}$. According to the data above, the compactness between the thermoelectric modules in Model \#1 was improved and the phenomenon of air gap was alleviated owing to the thermal resistance decreased after taking reinforcement measures. Therefore, the thermoelectric conversion efficiency and the output power of Model \#1 were increased.

\subsection{Effect of Heat Exchanger Insulation Measurements}

A low temperature environment leads to a large amount of heat loss and a low heat energy utilization rate. Model \#2, as shown in Figure 5b, was selected as the carrier to study the influence of heat-insulation measurements on output power, the insulation material was filled in the space between the heat exchanger and the thermoelectric modules thoroughly, then tested the output power respectively with insulation material or not. Heat insulation measurements can improve the output power about $5 \%$ according to the data listed in Figure 9.

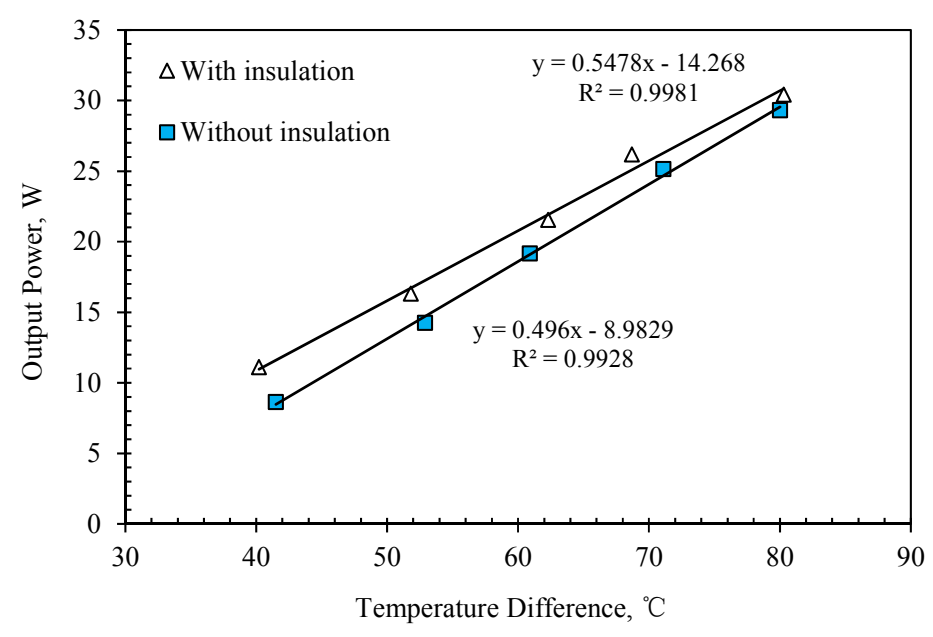

Figure 9. The effect of heat-insulation on output power. 


\subsection{Effect of Thermoelectric Module Connection Methods}

Thermoelectric modules are connected in series or parallel. In practical applications, when the same number of thermoelectric modules are connected, the more the thermoelectric modules are in series, the higher voltage is generated in the closed circuit, which reduces the voltage loss.

Model \#1 was chosen as carrier to study the effect of the connection method between the thermoelectric modules on the output power. In the experiments, the $\Delta T$ was maintained at $80{ }^{\circ} \mathrm{C}$ unchanged, the connection method was selected as Table 2, and the output power was obtained. The results are demonstrated in Figure 10.

Table 2. Different connection methods among 40 modules.

\begin{tabular}{cc}
\hline Mode & Connection Methods \\
\hline Mode 1 & 5 modules in series as one group, 8 groups as parallel \\
Mode 2 & 8 modules in series as one group, 5 groups as parallel \\
Mode 3 & 10 modules in series as one group, 4 groups as parallel \\
Mode 4 & 20 modules in series as one group, 2 groups as parallel \\
Mode 5 & 40 modules in series \\
\hline
\end{tabular}

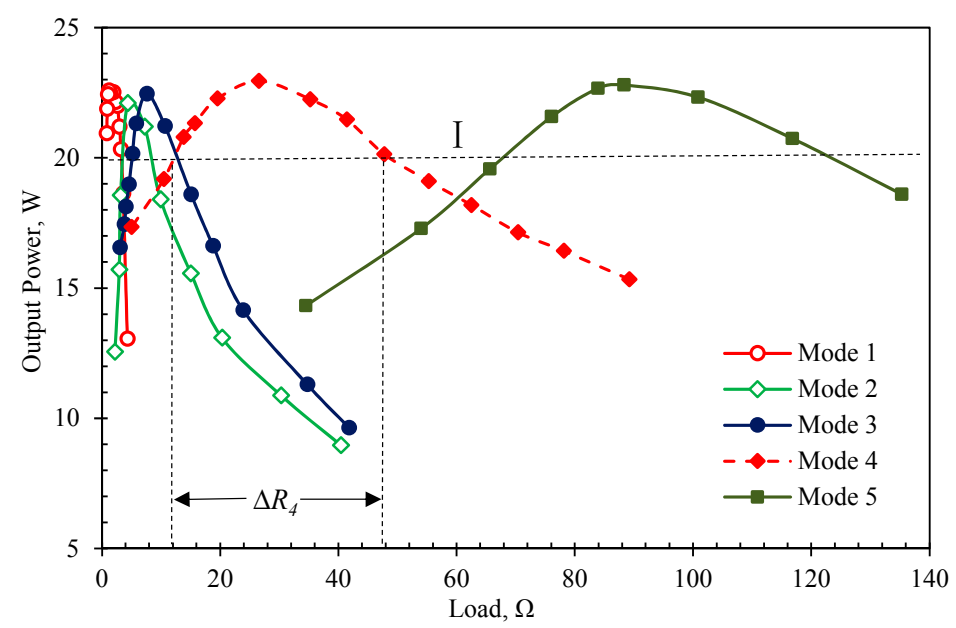

Figure 10. Relationship between output power and load for 40 modules with different connection methods $\left(\Delta T\right.$ is $\left.80^{\circ} \mathrm{C}\right)$.

The experimental data are briefly summarized as follows: the peak output power of Modes 1, 2, 3, 4 and 5 is $22.57,22.1,22.46,22.95$ and $22.79 \mathrm{~W}$ respectively, and the corresponding optimum resistances are $1.18,4.38,7.59,26.56$ and $88.29 \Omega$.

In order to study how the corresponding load changes when the peak output power is reduced about $10 \%$, we intercept the corresponding load for the $20 \mathrm{~W}$ shown as straight line I (Figure 10), and the results are listed in Table 3.

Table 3. Different $\Delta R_{i}$ for different connection methods.

\begin{tabular}{cccccc}
\hline Resistance & Mode 1 & Mode 2 & Mode 3 & Mode 4 & Mode 5 \\
\hline Optimum resistance value $(\Omega)$ & 1.18 & 4.38 & 7.59 & 26.56 & 88.29 \\
$\Delta R_{i}{ }^{1}$ & 3.06 & 5.03 & 7.66 & 36.53 & 50.8 \\
\hline
\end{tabular}

${ }^{1} \Delta R_{i}$ represents the variation range in the value of the resistance, when the power range changes $10 \%$.

It can be seen from Table 3 that $\Delta R_{1}$ is $3.06 \Omega$ as 40 thermoelectric modules connected in Mode 1 , while $\Delta R_{5}$ is $50.8 \Omega$ as 40 thermoelectric modules connected in Mode 5 , and $\Delta R_{i}$ also rise with the increasing number of thermoelectric module in series. These experimental results indicated that the 
connection modes between the thermoelectric modules may not affect the peak power of TEG when the quantity is the same.

\subsection{Effect of Fluid Flow Direction}

Figure 11a shows the case in which the heat fluid flow direction is the same as the cold fluid flow direction, that is, co-current, and the opposite is counter current (Figure 11b). Owing to the thinner wall of Model \#2 and relatively stable fluid flow in the cavity of the heat exchanger, Model \#2 was chosen as the carrier to investigate the influence of fluid flow direction on the output power. In the experiments, we controlled the $\Delta T$ from around 40 to $80^{\circ} \mathrm{C}$, held the flow rates through the hot and cold sides of the heat exchanger constant, selected Mode 5 as the connection method between the thermoelectric modules, and then tested the output power of Model \#2 at the different $\Delta T$ in the co-current and counter current. The experimental results are shown in Figure 12.

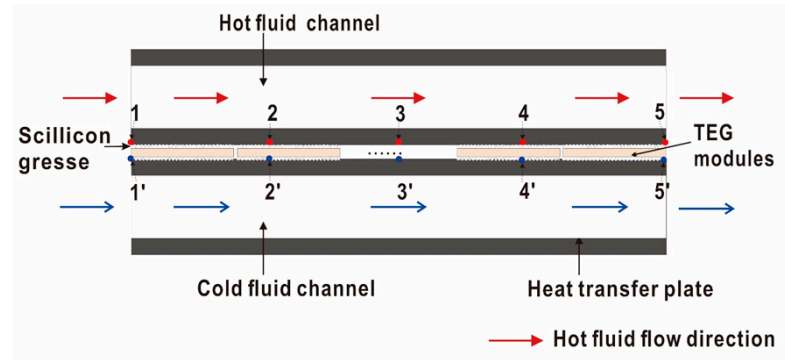

(a)

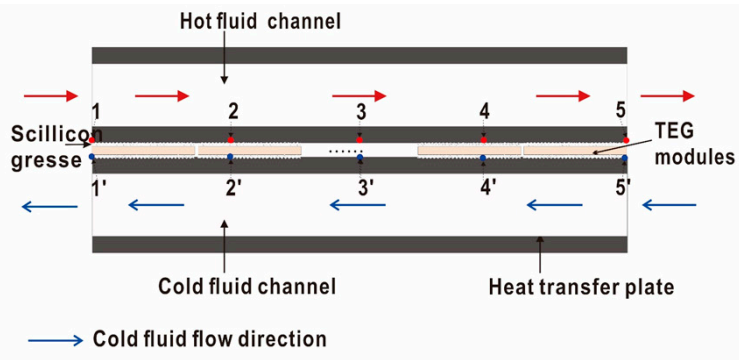

(b)

Figure 11. Fluid flow direction diagram: (a) Co-current; (b) Counter current (The dots in diagram are testing points).

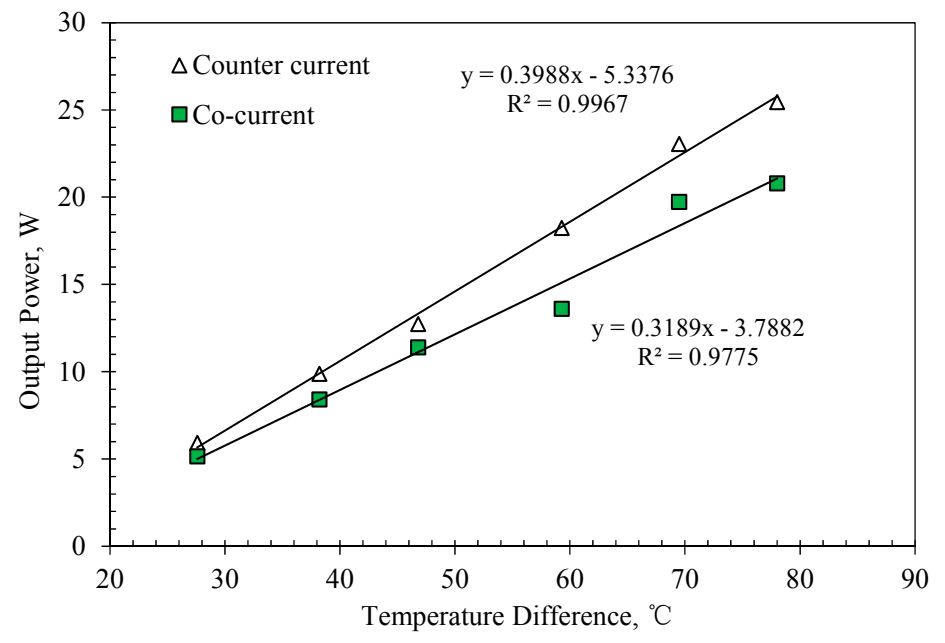

Figure 12. The effect of flow direction on output power.

Figure 12 demonstrates that the output power of the counter current is much higher than that of the co-current for the same TEG, when $\Delta T$ is the same. The thermal loss of the hot side and the thermal absorption of the cold side lead to this phenomenon when the TEG is working. For the hot side, the temperature at the inlet is higher than that at the outlet, while it is opposite for the cold side. Counter current may result in a closer temperature difference at the inlet and outlet, but co-current may enlarge this temperature difference (inlet temperature difference is greater than that at the outlet). The output voltage and current is different when the temperature difference of each module is not the same (as shown in Figure 13), and it leads to more consumption of thermal energy and less output 
power. Under the same conditions, the output power based on counter current flow mode is greater than that in the co-current flow mode.

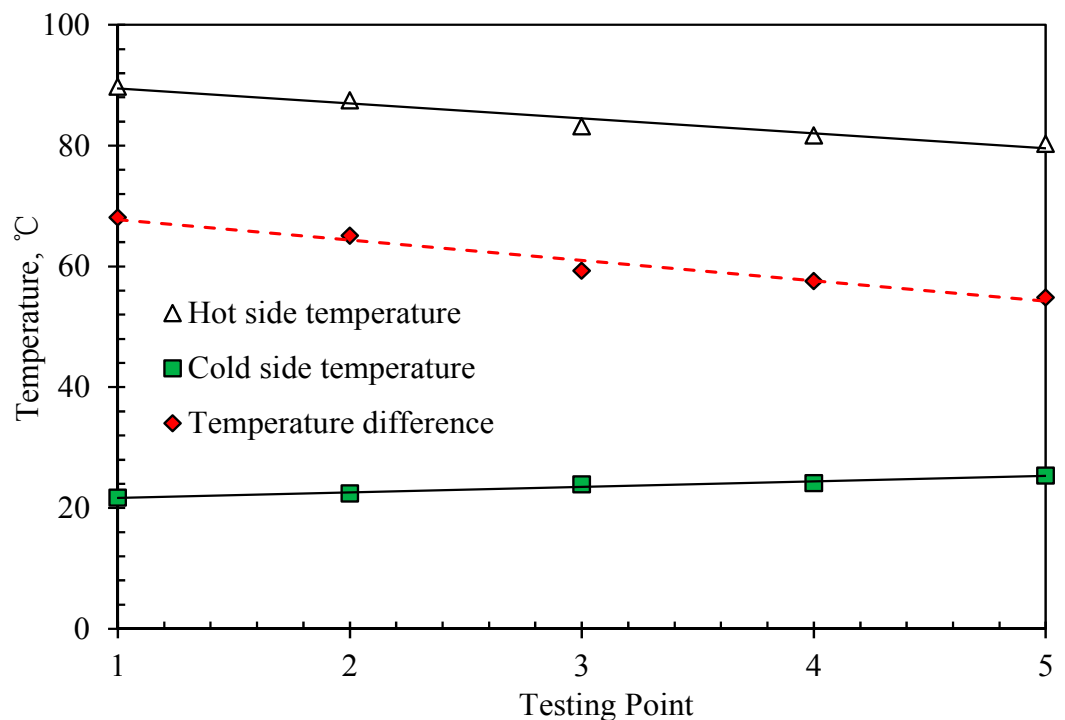

(a)

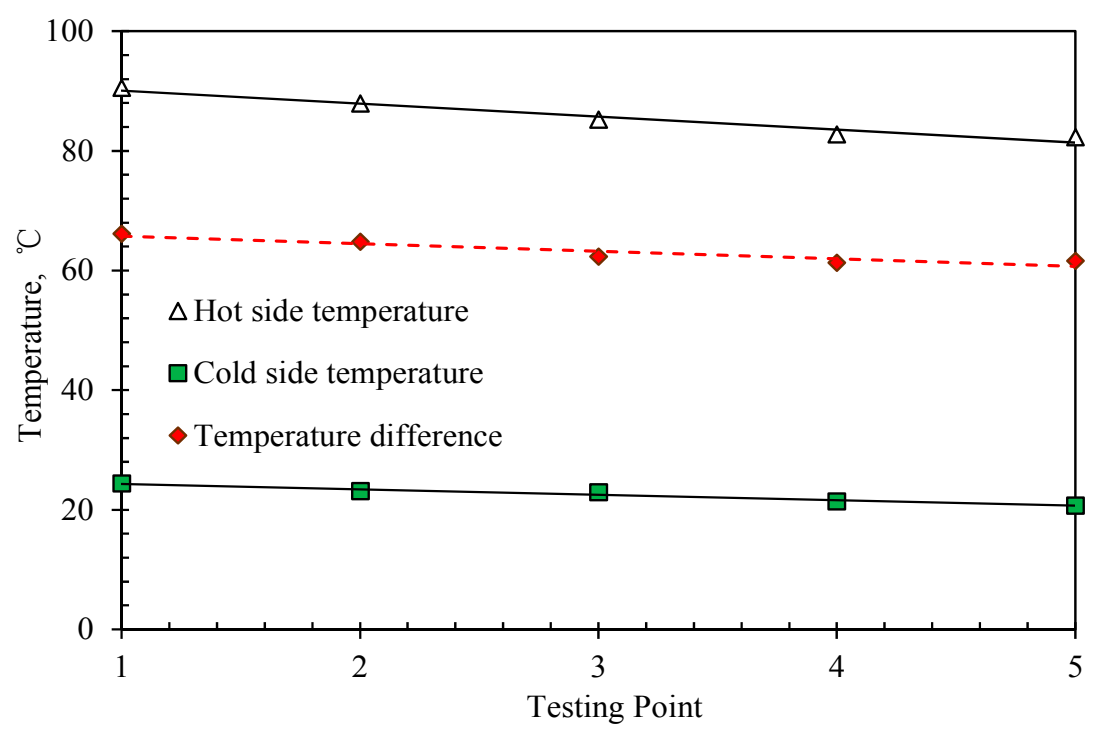

(b)

Figure 13. Temperature and temperature difference of each testing point for different flow direction:

(a) Co-current; (b) Counter current.

\subsection{Effect of Flow Rate}

After the wall of the fluid channel in Model \#3 has been treated to be rougher, the velocity of the fluid passing through the fluid channel is affected. As the influence of the volumetric flow rate at the inlet of the heat exchanger on the output power is likely to be more distinct, Model \#3 was chosen as the carrier to study the relationship between the flow rate of the inlet and the output power of TEG.

In the experiments, $\Delta T$ was maintained at a constant $50{ }^{\circ} \mathrm{C}$, the fluid flow direction in the heat exchanger plate was counter current. On one hand, the hot side inlet flow-rate was controlled at $18 \mathrm{~L} / \mathrm{min}$ unchanged, only adjusting the cold side inlet flow-rate from $1 \mathrm{~L} / \mathrm{min}$ to $14 \mathrm{~L} / \mathrm{min}$, and testing the output power of Model \#2 at each cold side flow-rate. Then $\Delta T$ was kept at around $70{ }^{\circ} \mathrm{C}$, the above experiment was repeated, and the experimental results are shown in Figure 14. On the other hand, we still controlled the $\Delta T$ in Model $\# 2$ at $50{ }^{\circ} \mathrm{C}$ but held the cold side inlet flow-rate constant, 
changing the hot side inlet flow-rate from $1 \mathrm{~L} / \mathrm{min}$ to $18 \mathrm{~L} / \mathrm{min}$, and tested the output power of Model \#2 in each flow rate at the hot inlet. The above experiments were repeated while keeping $\Delta T$ stabilized at around $70^{\circ} \mathrm{C}$. The experimental results are shown in Figure 15.

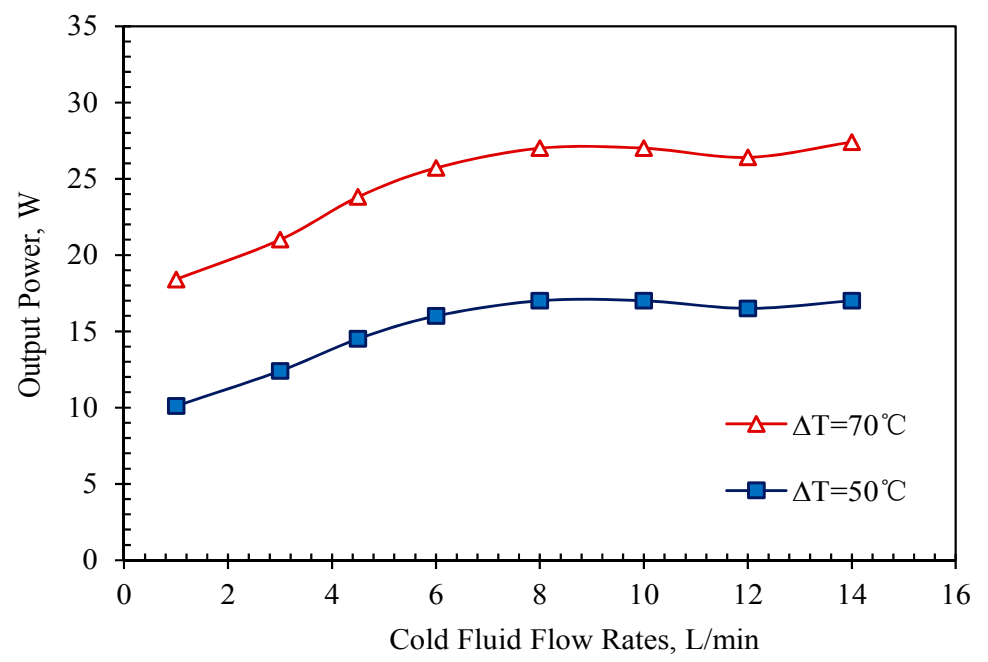

Figure 14. The effect of cold fluid flow rate on output power.

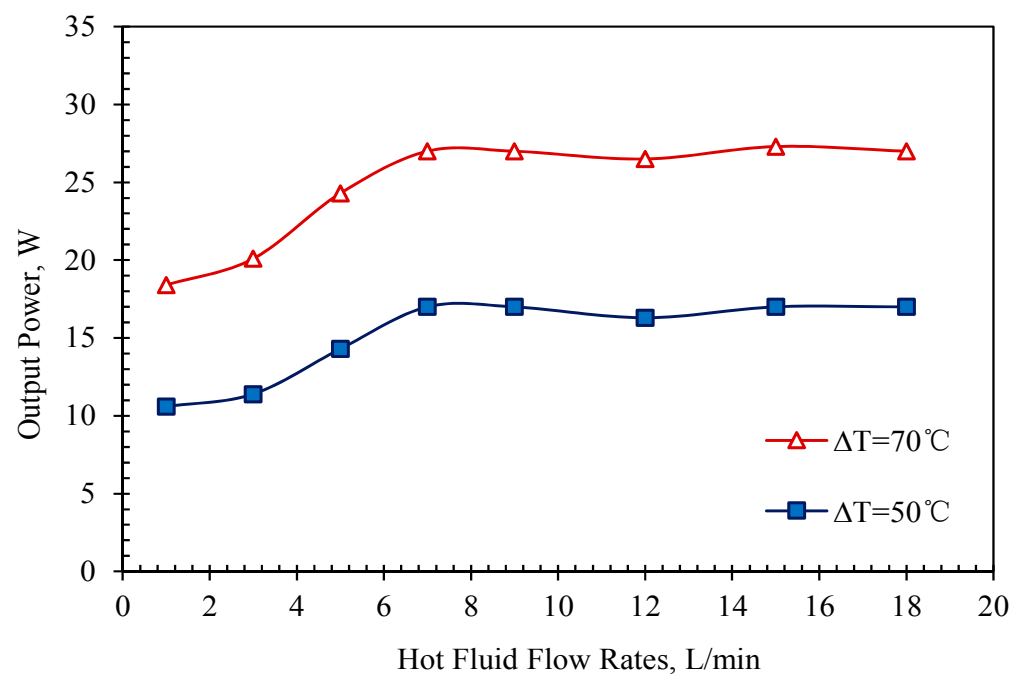

Figure 15. The effect of hot fluid flow rate on output power.

The inlet flow-rate of the hot side was constant, the output power increases first and then slowly becomes constant with the increase in the cold side inlet flow-rate. The hot inlet flow-rate is $18 \mathrm{~L} / \mathrm{min}$ and the cold inlet flow-rate is $8 \mathrm{~L} / \mathrm{min}$, the maximum output power of Model \#3 is $26.8 \mathrm{~W}$ under a $\Delta T$ of $70{ }^{\circ} \mathrm{C}$ (see Figure 14).

According to Figure 15, the output power also increases first and then tends to be stabilized with the increase of the hot side inlet flow-rate when the cold side inlet flow-rate is unchanged. When the $\Delta T$ is $70{ }^{\circ} \mathrm{C}$, the cold side inlet flow is $11.7 \mathrm{~L} / \mathrm{min}$ and the hot side inlet flow is $7 \mathrm{~L} / \mathrm{min}$, the output power of Model \#3 is maximized around $27.1 \mathrm{~W}$.

In summing up, when the inlet flow rate of the cold (hot) side of the heat exchanger is constant, with only the flow rate at the hot (cold) side increasing, the output power of the Model \#3 tends to be stable. The rise in output power is due to the fact that the heat transfer is improved while the inlet flow was increasing, but if the inlet flow continues to increase, the heat transfer tends to be balanced 
and reached the maximum. In TEG devices, there may exist an optimal flow rate. Fluid flow rates exceeding the optimal value may not bring more power output, but increase the self-consumption.

\section{Optimization Results}

Based on above optimization, an optimized model improved from Model \#3 was designed, built, and tested. The value of $\Delta T$ was controlled at $80^{\circ} \mathrm{C}$. On the basis of the fact that the more thermoelectric modules in series, the greater the total internal resistance consumption, Mode 4 (Table 3) was selected as the connection methods between thermoelectric modules. The fluid flow direction of the parallel heat exchange plates was counter current. The appropriate flow rate on the hot and cold sides of the heat exchanger was applied. The maximum output power and average maximum output power of Model \#3 was tested, and the comparison with the previously reported data [13] is presented in Figures 16 and 17.

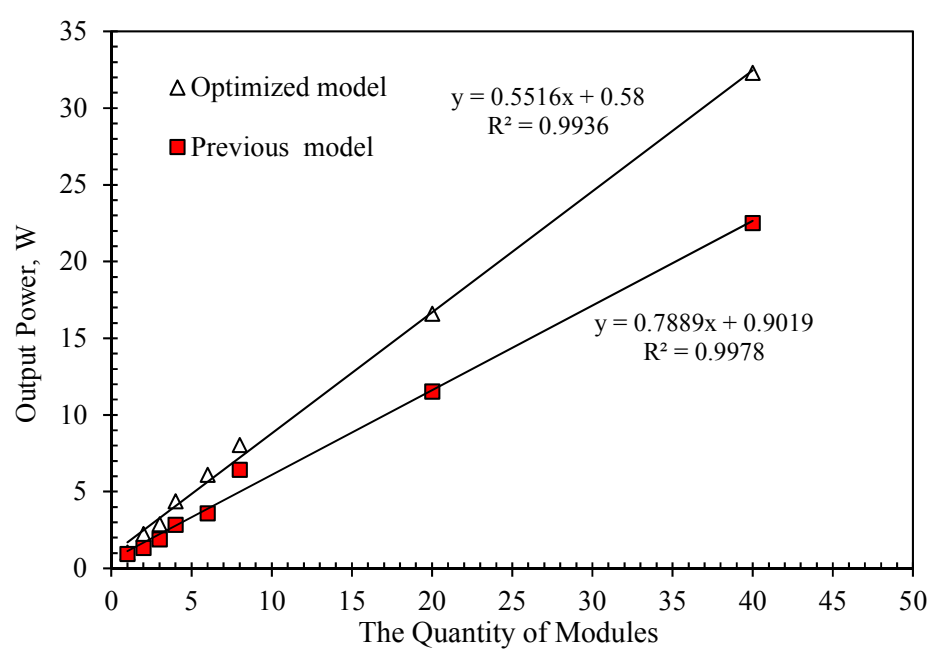

Figure 16. Maximum output power of the optimized model and previous model at different $\Delta T$.

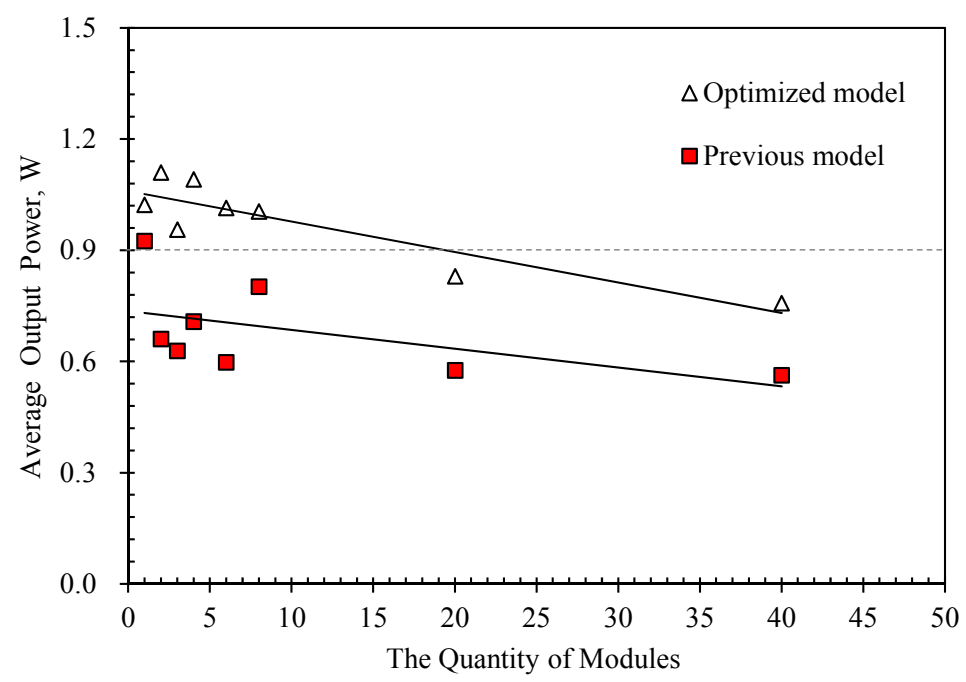

Figure 17. Average maximum output power of the optimized and previous models at different $\Delta T$.

As demonstrated in Figures 16 and 17, the output power of the optimized model has been enhanced by about $34.6 \%$ compared with the output power of the previous model [13], the instantaneous efficiency of the optimized TEG system could reach about $6.5 \%$ at the same temperature difference. 


\section{Conclusions}

(1) The experimental results show that the maximum output power is greatly affected by the operating conditions, especially the TEG apparatus structure, fluid flow direction and flow rates.

(2) The maximum output power is not affected by the connection patterns (series or parallel) of the modules, although the voltages may change.

(3) A TEG system has been designed, built, tested, and optimized. Experimental studies on the internal resistance of the TEG module and the main factors that affect the output power were conducted. Compared with the previously published system, the output power of the optimized TEG has increased more than $34.6 \%$ (from $22.5 \mathrm{~W}$ to $32.5 \mathrm{~W}$ for $40 \mathrm{TEG}$ modules); the instantaneous efficiency of the TEG system could reach about $6.5 \%$.

Acknowledgments: This research was conducted partially with financial support from China Pingmei Shenma Group, the contributions of which are gratefully acknowledged.

Author Contributions: K.L. conceived and designed the experiments; J.C. and C.L. designed and performed the experiments; M.L. and Y.L. contributed materials and tools; J.C., K.L., C.L., L.J. and S.J. conducted the data analysis and wrote the paper.

Conflicts of Interest: The authors declare no conflict of interest.

\section{References}

1. Wright, P.M. The sustainability of production from geothermal resources. Bull. Geo-Heat Cent. 1998, 19, 9-12.

2. Tang, X.; Zhang, J.; Pang, Z.; Hu, S.; Wu, Y.; Bao, S. Distribution and genesis of the eastern Tibetan Plateau geothermal belt, western China. Environ. Earth Sci. 2017, 76, 31. [CrossRef]

3. Lund, J.W.; Freeston, D.H.; Boyd, T.L. Direct application of geothermal energy: 2005 worldwide review. Geothermics 2005, 34, 691-727. [CrossRef]

4. Lund, J.W.; Bjelm, L.; Bloomquist, G.; Mortensen, A.K. Characteristics, development and utilization of geothermal resources-A Nordic perspective. Episodes 2008, 31, 140-147.

5. Kalina, A.I. Combined cycle and waste heat recovery power systems based on a novel thermodynamic energy cycle utilizing low-temperature heat for power generation. In Proceedings of the 1983 Joint Power Generation Conference, Indianapolis, IN, USA, 25-29 September 1983.

6. Khaliq, A.; Kumar, R.; Dincer, I. Performance analysis of an industrial waste heat-based trigeneration system. Int. J. Energy Res. 2009, 33, 737-744. [CrossRef]

7. Poran, A.; Tartakovsky, L. Performance and emissions of a direct injection internal combustion engine devised for joint operating with high-pressure thermochemical recuperation system. Energy 2017, 124, 214-226. [CrossRef]

8. Pashchenko, D.I. Thermochemical recovery of heat contained in flue gases by means of bioethanol conversion. Therm. Eng. 2013, 60, 438-443. [CrossRef]

9. Poran, A.; Artoul, M.; Sheintuch, M.; Tartakovsky, L. Modeling internal combustion engine with thermo-chemical recuperation of the waste heat by methanol steam reforming. SAE Int. J. Engines 2014, 7, 234-242. [CrossRef]

10. Javani, N.; Dincer, I.; Naterer, G.F. Thermodynamic analysis of waste heat recovery for cooling systems in hybrid and electric vehicles. Energy 2012, 46, 109-116. [CrossRef]

11. Noie-Baghban, S.H.; Majideian, G.R. Waste heat recovery using heat pipe heat exchanger (HPHE) for surgery rooms in hospitals. Appl. Therm. Eng. 2000, 20, 1271-1282. [CrossRef]

12. Li, K.; Bian, H.; Liu, C. Comparison of geothermal with solar and wind power generation systems. Renew. Sustain. Energy Rev. 2015, 42, 1464-1474. [CrossRef]

13. Liu, C.; Chen, P.; Li, K. A 500W low-temperature thermoelectric generator: Design and experimental study. Int. J. Hydrog. Energy 2014, 39, 15497-15505. [CrossRef]

14. Godart, C.; Gonçalves, A.P.; Lopes, E.B.; Villeroy, B. Role of structures on thermal conductivity in thermoelectric materials. In Properties and Applications of Thermoelectric Materials; Veljko, Z., Alex, C.H., Eds.; Springer: Berlin, Germany, 2009; pp. 19-49. 
15. Zheng, X.F.; Liu, C.X.; Yan, Y.Y. A review of thermoelectric research-Recent developments and potentials for sustainable and renewable energy applications. Renew. Sustain. Energy Rev. 2014, 486-503. [CrossRef]

16. Demir, M.E.; Dincer, I. Development of an integrated hybrid solar thermal power system with thermoelectric generator for desalination and power production. Desalination 2017, 404, 59-71. [CrossRef]

17. Xing, N.; Yu, J.; Wang, S. Experimental study on low-temperature waste heat thermoelectric generator. J. Power Sources 2009, 188, 621-626.

18. Chen, L.; Gong, J.; Sun, F. Effect of heat transfer on the performance of thermoelectric generators. Int. J. Therm. Sci. 2002, 41, 95-99. [CrossRef]

19. Crane, D.T.; Jackson, G.S. Optimization of cross flow heat exchangers for thermoelectric waste heat recovery. Energy Convers. Manag. 2004, 45, 1565-1582. [CrossRef]

20. Hsu, C.T.; Huang, G.Y.; Chu, H.S. Experiments and simulations on low-temperature waste heat harvesting system by thermoelectric power generators. Appl. Energy 2011, 88, 1291-1297. [CrossRef]

21. Rodríguez, A.; Vián, J.G.; Astrain, D. Study of thermoelectric systems applied to electric power generation. Energy Convers. Manag. 2009, 50, 1236-1243. [CrossRef]

22. Bélanger, S.; Gosselin, L. Thermoelectric generator sandwiched in a cross flow heat exchanger with optimal connectivity between modules. Energy Convers. Manag. 2011, 52, 2911-2918. [CrossRef]

23. Ming, T.; Wu, Y.; Peng, C. Thermal analysis on a segmented thermoelectric generator. Energy 2015, 80, 388-399. [CrossRef]

24. Esarte, J.; Min, G.; Rowe, D.M. Modelling heat exchangers for thermoelectric generators. J. Power Sources 2001, 93, 72-76. [CrossRef]

25. Gou, X.; Xiao, H.; Yang, S. Modeling, experimental study and optimization on low-temperature waste heat thermoelectric generator system. Appl. Energy 2010, 87, 3131-3136. [CrossRef]

26. Casano, G.; Piva, S. Experimental investigation of the performance of a thermoelectric generator based on Peltier cells. Exp. Therm. Fluid Sci. 2011, 35, 660-669. [CrossRef]

27. Chen, M.; Rosendahl, L.A.; Condra, T. A three dimensional numerical model of thermoelectric generators in fluid power systems. Int. J. Heat Mass Transf. 2011, 54, 345-355. [CrossRef]

28. Yu, J.; Zhao, H. A numerical model for thermoelectric generator with the parallel-plate heat exchanger. J. Power Sources 2007, 172, 428-434. [CrossRef]

29. Meng, F.; Chen, L.; Sun, F. A numerical model and comparative investigation of a thermoelectric generator with multi-irreversibilities. Fuel Energy Abstr. 2011, 36, 3513-3522. [CrossRef]

30. Gou, X.; Yang, S.; Xiao, H. A dynamic model for thermoelectric generator applied in waste heat recovery. Energy 2013, 52, 201-209. [CrossRef]

31. Twaha, S.; Zhu, J.; Yan, Y. Performance analysis of thermoelectric generator using dc-dc converter with incremental conductance based maximum power point tracking. Energy Sustain. Dev. 2017, 37, 86-98. [CrossRef]

32. Putri, R.I.; Wibowo, S.; Rifa, I.M. Maximum Power Point Tracking for Photovoltaic Using Incremental Conductance Method. Energy Proced. 2015, 68, 22-30. [CrossRef]

33. Seif, S.; Thundat, T.; Cadien, K. Evaluation of efficiency factors and internal resistance of thermoelectric materials. Int. J. Energy Res. 2016, 41, 198-206. [CrossRef]

(C) 2017 by the authors. Licensee MDPI, Basel, Switzerland. This article is an open access article distributed under the terms and conditions of the Creative Commons Attribution (CC BY) license (http:/ / creativecommons.org/licenses/by/4.0/). 